\title{
Teacher Written vs. Audio Feedback on Undergraduates' Written Assignments
}

\author{
Mohammed Abdullah Alharbi \\ Department of English, College of Education, Majmaah University, Majmaah, Saudi Arabia
}

Abdurrazzag Alghammas

Department of English Language and Translation, College of Arabic Language and Social Studies, Qassim University, Saudi Arabia

\begin{abstract}
Due to the importance of instructor's feedback on students' written assignment as part of formative assessment and the relatively new way of delivering audio feedback, this case study aimed to explore instructor's audio vs. written feedback provided on 15 pairs of undergraduates' written tasks through Google Docs over an academic semester in a Saudi public university. The data was collected from actual feedback comments in both modes and follow-up interviews with the students. The content analysis of feedback revealed that audio feedback differed from written feedback in terms of quantity and content. Despite the potential of audio feedback revealed through the content analysis, the majority of students (16) preferred written feedback over audio feedback for its clarity, easiness, easy access to feedback and its focus on a certain issue in the assignments, whereas 14 of them preferred audio feedback. Several challenges highlighted by the students, including its length and detailed instruction and the difficulty in accessing it served as good points for several pedagogical implications for instructors in this study.
\end{abstract}

Index Terms - feedback, audio feedback, written feedback, peer review, L2 writing

\section{INTRODUCTION}

Teacher feedback is an essential part or component of teaching, especially in writing classroom instruction (Dixon, 2015). It has been documented as an effective way of teachers'/instructors' formative assessment of students' writing or written tasks and assignments in various undergraduate courses, including writing in higher education (Cavanaugh \& Song, 2014; Dixon, 2015). Feedback is a type of teachers' scaffolding to students to achieve certain goals (e.g., successful accomplishment of written tasks) that they may not be able to do alone (Hyland, 2010; Hyland \& Hyland, 2006; Gould \& Day, 2013; Lee, 2014). Effective teacher feedback related to the goals and outcomes specified in a given course (Nicol \& MacFarlane-Dick 2006). The effect of teachers' effective feedback on students' assignments is even associated with students' future learning (Hennessy \& Gillian Forrester, 2014).

Due to the importance of teachers' feedback on students' assignments, many researchers have explored the way feedback should be composed and provided to students. Specifically, whether teachers should deliver their feedback in written comments or audio records has attracted the attention of those researchers. In order to explore this interesting research topic, studies have compared and evaluated both modes of teacher feedback on students' assignments in different courses and disciplines (Fawcett \& Oldfield, 2016; Hennessy \& Forrester, 2014; Ice et al., 2010; RodwayDyer, Knight, and Dunne 2011). Most of these studies provided evidence of the efficacy of audio feedback, especially when combined with written feedback. Certain advantages of audio feedback as perceived by students include clarify, simplicity in terms of the language used, detailed instruction on students' issues and flaws in their written tasks and useful suggestions and explanations (Lunt \& Curran, 2010; Olesova et al., 2011; Rodway-Dyer et al., 2011; Parkes \& Fletcher, 2016; Voelkel \& Mello, 2014).

Yet, most of these studies have reported such findings on the advantages of audio feedback from students' perceptions through questionnaires, interviews and even focus group discussions as reflections at the end of courses. According to Macgregor, Spiers, and Taylor (2011), while previous research has reported students' perception of audio feedback as quality or good feedback, there is still a need for a comprehensive investigation of the effectiveness of audio feedback in students' learning. Such comparison between both modes of teacher feedback could have been enriching if analysis of the actual feedback practices had been implemented in most previous research. This is crucial especially since "the advent of audio feedback technology is relatively new and its use in higher education as a vehicle for feedback is in its infancy. Consequently, there is not a substantial body of research on the subject" (Lunt \& Curran, 2010, p. 760). Therefore, the present study attempted to explore teacher's audio vs. written feedback from both an actual analysis of teacher feedback and from students' perspectives by answering the following two research questions:

1. How does the audio feedback differ from the written feedback provided by the instructor on undergraduates' written assignments in relation to its amount and content?

2. How did the undergraduates view both types of teacher feedback provided on their writing? 


\section{LITERATURE REVIEW}

Theory: Teacher/instructor feedback has been conceptualized in previous research as a type of scaffolding or assistance provided to student in successfully accomplishing their tasks that they may not be able to complete independently (e.g., Hyland, 2010; Hyland \& Hyland, 2006; Lee, 2014). Such conceptualization of feedback as scaffolding is founded on the sociocultural theory of learning (Vygotsk, 1978). This theory provides insights into the process of mediated learning and the zone of proximal development (ZPD). As learners engage in learning through collaboration with others (e.g., teachers or peers), they are assisted (e.g., verbal assistance or assistance through language) not only to do certain tasks but also to progress in their learning and achieve higher levels of ZPD (Aljaafreh \& Lantolf, 1994; Hyland \& Hyland, 2006; Nassaji \& Swain, 2000). From this theory, feedback assists learners to detect the issues and flaws in their written tasks and also helps them to correct such issues and enhance their tasks.

Previous studies on audio vs. written feedback: Recently, due to the increasing revolution of technology in higher education, many researchers have explored the potential of instructors' audio feedback and even compared it to written feedback on students' written assignments in various courses and disciplines (e.g., Fawcett \& Oldfield, 2016; Hennessy \& Forrester, 2014; Ice et al., 2010; Rodway-Dyer, Knight, and Dunne 2011). Most earlier studies focusing on students' perception and experiences in receiving audio vs. written feedback reported students' highly positive perception of or preference for audio feedback over written feedback (Fawcett \& Oldfield, 2016; Hennessy \& Forrester, 2014; Ice et al., 2010; Lunt \& Curran, 2010; Olesova et al., 2011; Rodway-Dyer et al., 2011; Parkes \& Fletcher, 2016; Voelkel \& Mello, 2014).

These above studies supporting the potential of audio feedback also documented certain features or advantages of audio feedback perceived by students. For instance, according to Rodway-Dyer et al., (2011), audio feedback is timeeffective, applicable to different types of assessment and tailored to the needs of individual learners or groups and understandable. For Hennessy and Forrester (2014), the perceived the advantages of audio feedback include its effectiveness, inclusion of less technical language and provision of detailed instruction. As reported by Parkes and Fletcher (2016), the positive features of audio feedback perceived by the students are its clarity, easiness, identification of areas of strengths and weakness in students' assignments and being personal.

Moreover, Voelkel \& Mello (2014) found that audio feedback was associated with students' satisfaction, particularly in relation to the amount of feedback, details and clarity. It was also interesting that it is not only the detailed nature of audio feedback that was identified by Lunt and Curran (2010), but also the poor standard of written feedback students received which were the main reasons behind their preference for audio feedback. Audio feedback was also preferred by students for it involved students in better learning of the course content (Olesova et al., 2011).

Some previous researchers reported that students' preference for audio vs. written feedback differed according to the foci/content of feedback. For instance, Ice et al. (2010) found that while the combination of audio and written feedback was preferred by students at all levels. On the other hand, most of the students preferred receiving written feedback over audio feedback focusing on the micro-level issues. The reasons behind this preference could be due to the focus of written feedback on one instance of poor spelling and grammar, whereas audio feedback providing a detailed instruction on each point or issue confuses students. This finding supports the findings reported by According to Still (2006) who found that the majority of students preferred receiving written feedback on their grammar and spelling-related issues.

Some studies have also reported contradicting findings on the potential of audio feedback, which also highlighted its disadvantages. Fawcett and Oldfield (2016) found that the students showed a significantly higher preference for written feedback over audio feedback. The students' experiences in the quality of feedback did not significantly differ between those receiving either audio or written feedback. The researchers justified such findings by stating that the standard of the written feedback (well-written feedback as opposed to hand-written feedback in early studies) could prevent students from perceiving the higher quality of audio feedback over the written feedback and also the experimental nature of the study as opposed to most previous studies.

According to Johnson and Cooke (2015), the majority of students preferred written feedback over audio feedback. They also justified their preference by stating that they could easily refer to written feedback as opposed to audio feedback that requires downloading. The researchers attributed such finding to the skills and comfort of tutors in recording their feedback. In a study by Olesova et al. (2011), most students perceived written feedback more effective than audio feedback due to the visual support the written feedback provides. Voelkel and Mello (2014) found that that students' referring to written feedback was higher than their referring to audio feedback, which could be due to the easiness involved in re-reading the written feedback as opposed to re-listening to the audio feedback.

\section{Methodology}

Research design: The current study adopted a qualitative research approach, specifically an exploratory case study. Such approach suits the aim of the present study, particularly exploring the audio feedback as part of instructor's feedback (Gould \& Day, 2013). Thus, the case study reported in this paper is context bound since it focuses on a particular undergraduate course in a Saudi public university.

Study setting and participants: The study was conducted among 30 undergraduates joining a linguistic course at the third year of their undergraduate program at the Department of English in a Saudi public university. The university 
campus where the study was carried out was especially for male students so all participants in this study are male Saudi students. The participants were joining the English Bachelor Program in Education and they speak English as a foreign language (EFL), while their first language (L1) is Arabic. The course they were joining reported in this study aims to enable students acquire knowledge about linguistics in English. However, the task assigned to them, the main focus of this study, is a critique of two papers focusing on topic related to linguistic analysis of morphological and syntactic features of a text in English.

Study procedure: Prior to the study procedure, the learners were informed of the purpose of this study and for ethical considerations, they signed a written form each student. They were also informed of the follow-up interviews and assured of protecting their confidentiality. The participating students joining the course were assigned to critique writing. They were instructed on the task as one of the tasks required for the evaluation of their performance in this course at the start of the semester. The students were assigned to start working on the task from the fourth week of the semester till the thirteenth week when they had to submit their final drafts for evaluation. However, since the task was effort-demanding, the students were assigned in 15 pairs. They were given the chance to select their peers and their topics of the tasks. Then, the instructor taught them how to use Google Docs via their mobiles in the classroom. He also created 15 Google Docs pages and shared each page with its respective pair of students. Once they finished writing the first draft (Week 10), each pair uploaded the draft in their Google Docs page for the instructor to give feedback. At this first stage, the instructor read all drafts and provided feedback, while each pair had to revise the task based on the written feedback.

As they finished revision, the instructor read the revised drafts to check students' revisions based on the written feedback, then the second stage (audio feedback) started. The feedback was recorded by the instructor's through mobile using Talk \&Comment for Android. Once he finished recording each feedback, he could copy the link and posted it in the form of written comment in the Google Docs that was immediately converted into audio once the students' playing program was on. The students were also trained on how to play and listen to sample audio feedback. This stage lasted till the thirteenth week when all pairs received audio feedback from the instructor and revised their tasks as final versions to be submitted for evaluation.

Data collection: The data was collected from the instructors' feedback on students' written tasks and follow-up interviews with the students. For the first type of data, the feedback comprised the instructors' written and audio feedback comments. This data was archived in the Google Docs pages of the 15 pairs of students. Once each pair revised the draft in both stages based on the written feedback and audio feedback, respectively, they were asked to upload their revised draft in the form of word file, but they were not allowed to delete the feedback comments from the Google Docs since this data later was analyzed. While the instructor's written feedback was collected at the end of the first stage, the audio feedback was collected at the end of the second stage. Both modes of data were archived and subjected for analysis later.

For the second type of data, the students were interviewed at the last week of the semester by another researcher. The follow-up interview consisted of five structured questions that were prepared prior to the interview meeting. The questions focused on eliciting students' reflections on their experiences in receiving audio vs. written feedback as well as their preferences for modes of feedback, justifications behind their preferences and their likes and dislikes for both modes of feedback. However, there were also a few other questions seeking clarifications, elaboration and justifications of their views were asked during the interview meeting. The students were interviewed individually, and the entire interview session lasted almost for five hours. It was recorded using the researcher's mobile recording voice.

Data analysis: Prior to the analysis of the instructor's actual feedback, the audio recorded comments were listened to by the instructor and another colleague. Then, the comments were transcribed and were organized along with the written feedback in word files. This made it easier for us to read the comments carefully, compare and contrast the audio and written feedback. The actual analysis was initiated by counting the overall number of audio recorded comments $(n=97)$ and written feedback comments $(n=520)$ provided on the students' written tasks over the semester. However, since this quantitative content analysis was not sufficient for our comparison and it was intended to focus on the quantity of both modes of feedback, we needed to compare both feedbacks in terms of its content.

In carrying out the qualitative content analysis of feedback, we referred to other studies on teacher written feedback because most of the above studies comparing audio and written feedback approached this topic from the students' perspectives or perceptions. Regarding this, first we coded each comment (audio and written) in relation to its language/pragmatic functions (e.g., question, directive, suggestion and so forth). However, our purpose from this qualitative analysis of feedback was not to identify the language functions of feedback rather than looking at whether each single commentary feedback constitutes up one or more language functions. From this analysis, we could observe that while for the audio feedback, each recorded comment composed more than one pragmatic function, for the written feedback, 490 comments composed only one pragmatic function each and only 30 comments consisted of more than one language function each (See the samples in the finding section).

The qualitative content analysis was pursued, but this time, our focus was to code the feedback in relation to its foci: what aspect of writing does each commentary feedback target or focus on? Although the framework for coding the feedback in terms of its foci was adopted from previous research on teacher written feedback, we attempted to adjust it into these categories according to our instruction and assessment of students' tasks: content, organization, linguistic 
accuracy and requirements. We also looked at whether each commentary feedback in both modes focused on a single issue or a combination of issues. Based on this, we observed that whereas each feedback in the audio data focused on more than issue, thus targeting an overall number of 334 issues, each comment in the written feedback focused on a single issue, thus targeting an overall number of 520 issues.

\section{FINDINGS}

Audio feedback vs. written feedback: To answer the first question, the findings of the study are reported and interpreted according to our analysis of both types of feedback in terms of quantity and content:

Quantity of feedback provided: Our analysis of the data was initiated by conducting a quantitative enquiry of the audio vs written feedback provided on the assignments of the ten pairs of students over the academic semester. The focus of this quantitative analysis was exclusive to the number of audio vs. written comments. The findings (Table 1) show that the number of written commentary feedback (520) exceeded the number of audio feedback. However, this led us to carry out an extensive content analysis of both types of feedback in order to gain better understanding of the pragmatic constituents of such feedback and the issues and flaws in students' writing the feedback addressed or targeted. The findings are reported in the second sub-section.

TABLE 1

THE OVERALL NumBer OF FEEDBACK IN ITS BOTH MODES

\begin{tabular}{|c|c|} 
THE OVERALL NUMBER OF FEEDBACK IN ITS BOTH MODES \\
\begin{tabular}{|c|c|}
\hline Mode of feedback comments & Number \\
\hline Audio feedback & 97 \\
\hline Written feedback & 520 \\
\hline
\end{tabular}
\end{tabular}

Content of feedback: Based on our substantial content analysis of the pragmatic constituents of the audio vs. written feedback comments quantified above, we found that whereas in all the audio comments (97), each recorded comment tended to be composed of several pragmatic functions, only 30 written comments combined more than one pragmatic functions each, and the remaining comments (490) carried out only one pragmatic function each. The following two example of the transcribed audio feedback illustrates how the instructor could diversify the feedback linguistically from statement, asking question, advice or suggestion to justification. So this audio of almost a medium size carried out four different pragmatic functions:

Here I think you have already used the full name of this approach in the earlier par graph so why again using it? You should use the abbreviated name of it here because the reader is familiar with it.

On the other hand, the written comments (30), which were found to be composed of more than one pragmatic function each, usually the instructor combined two different pragmatic functions (e.g., suggestion $\&$ question, statement \& question, praise \& question, evaluation \& suggestion, and so forth). This is illustrated by the following written commentary feedback which is a combination of praise and a question seeking an addition of a sentence to the introduction to state the purpose of the paper:

A great introduction you wrote. But can you add one sentence stating the aim of your paper to the reader at the end of your introduction?

We also calculated the overall number of pragmatic functions composing the audio vs. written feedback. Based on this, the overall number of audio feedback comments (97) contained an overall number of 351 pragmatic functions. This implies that the instructor could linguistically diversify his feedback in each audio feedback and could convey a higher number of diverse linguistic functions in a low number of audio comments. In contrast, the number of pragmatic functions carried out by the written feedback reached only 550 despite its higher number of comments provided. This finding also illustrates that each audio feedback contained more than three functions, while the written feedback (30) contained only two functions each.

TABLE 2

The Overall Number Of FeEdBack COMPosed Of Single And Multiple PRAGMatic Functions In Both Modes

\begin{tabular}{|c|c|c|c|}
\hline Mode of feedback & $\begin{array}{c}\text { Composed of a single } \\
\text { pragmatic function }\end{array}$ & $\begin{array}{c}\text { Composed of more than one } \\
\text { pragmatic function }\end{array}$ & $\begin{array}{c}\text { Overall number of pragmatic } \\
\text { functions }\end{array}$ \\
\hline Oral feedback (97) & 0 & 97 & 351 \\
\hline Written feedback (520) & 490 & 30 & 550 \\
\hline
\end{tabular}

Since the content of feedback is an important feature of effective teacher feedback, we analyzed the audio vs. written comments in relation to the foci or issues and flaws it addressed. Two important features of audio feedback were identified: being elaborative or detailed and focusing on multiple issues rather than a single issue each. For the first feature, we noticed that in most of the audio feedback, the instructor did not only point at the issue (s) detected in students' written assignments, but he also elaborated it or provided a detailed explanation on it (Table 3). Although this feature was observed in some written comments, they were not as elaborative as audio feedback. For instance, the following two sample comments demonstrate how the audio feedback comments were larger and more elaborative and detailed than written comments. 
TABLE 3

SAMPLE AUDIO VS. FEEDBACK IN RELATION TO ITS INSTRUCTION

\begin{tabular}{|c|l|}
\hline Mode of feedback & \multicolumn{1}{c|}{ Samples } \\
\hline Oral feedback & $\begin{array}{l}\text { Hi see the highlighted sentence structure. Of course, you have used three sentences together } \\
\text { without any connecting word. You did not even stop at the end of each sentence. Such sentences } \\
\text { are run-on-sentences. In order to fix them, remember to read each sentence and when you feel that } \\
\text { it gives you a complete idea, then put a full stop or connect it with another sentence to make a } \\
\text { compound sentence, using and, but or so etc. I hope you get my point here. }\end{array}$ \\
\hline Written feedback & Sure about this sentence structure? Please check it and correct it. \\
\hline
\end{tabular}

From the above two comments, while the audio feedback provided a mini lesson on the issue of sentence structure, including identification of the error, explanation of its nature and suggestions on how to fix it, the written feedback, in the form of a question and a directive, just pointed at the issue, but did not inform the students of what was exactly wrong with its structure.

For the second feature related to the focus of feedback on the issues and flaws in students' written assignments, it was found that most of the audio feedback (86) focused on multiple issues. In other words, each audio recorded comment addressed several issues and flaws varying from content, organization, language to requirements. In contrast, in all written feedback, each comment focused on a single issue. The following shots of audio feedback and written feedback in Table (4) provided by the instructor on one pair of students demonstrate how one audio feedback focused on multiple issues: appropriate vocabulary, grammar, sentence structure and idea expression, whereas each written comment of the three comments targeted only one single issue related to the linguistic accuracy (e.g., the first written feedback focused on the use of "but" in a sentence initiated by "although").

TABLE 4

SAMPLE AUdio Vs. FEEDBACK In RELATION TO ITS FOCUS ON ISSUES IN STUDENTS’ TASKS

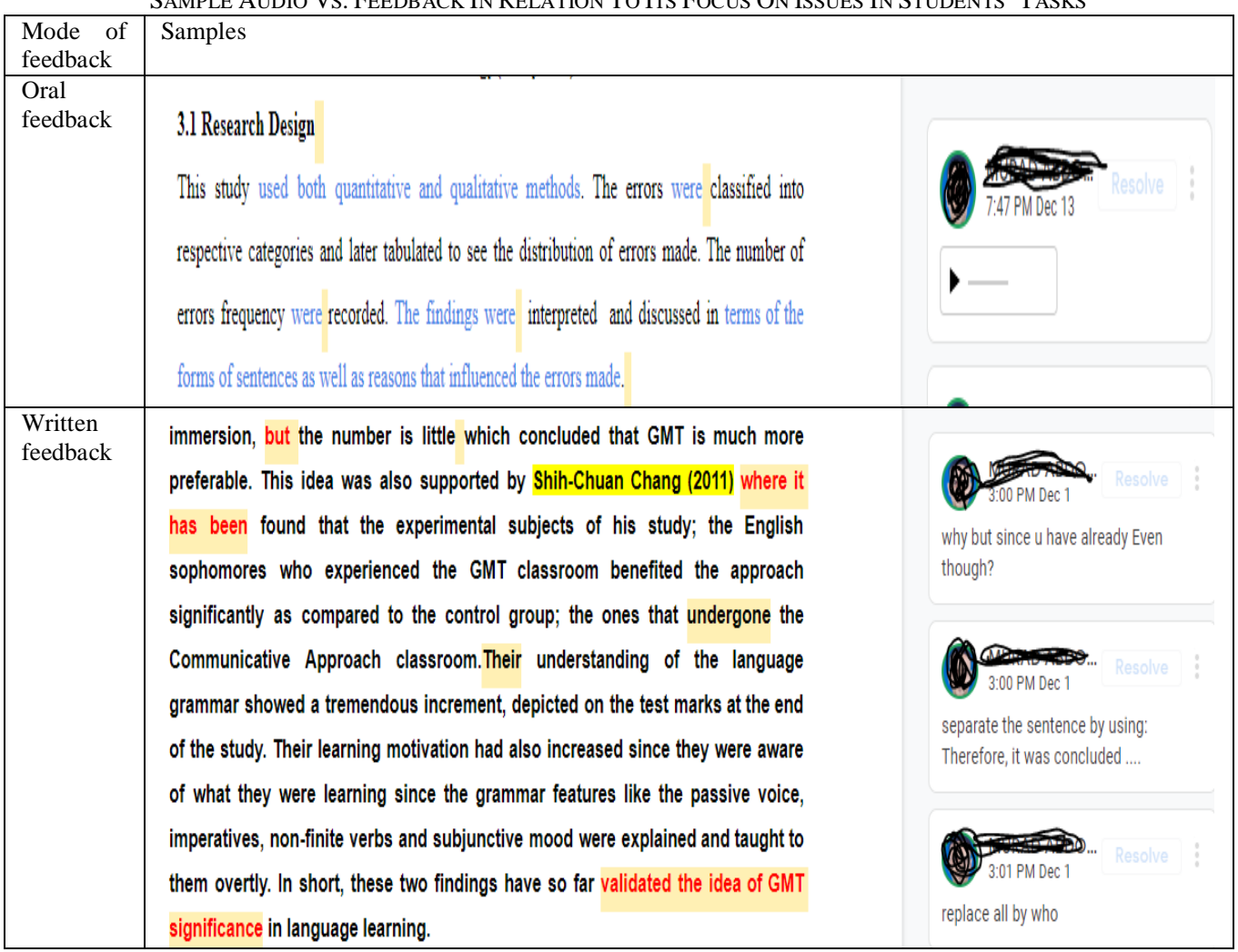

From the above examples, we could confirm that each audio feedback targeted several issues and flaws in students' written assignments, while each written feedback targeted a single issue. This is all supported by our quantitative enquiry of the issues targeted by both types of feedback. Based on the analysis of the overall number of audio vs. written feedback provided over the academic semester (Table 5), the overall number of the audio feedback (97) targeted a number of 334 issues in students' assignments, varying from content (52), organization (24), linguistic accuracy (211) and requirements (47). On the other hand, the overall number of written feedback (520) targeted a number of 520 issues distributed as 61 for content, 49 for organization, 304 for linguistic accuracy and 106 for requirements. 
TABLE 5

THE OVERALl Number Of IsSues TARGeTEd By FeEdBack In Both Modes

\begin{tabular}{|c|c|c|c|c|c|}
\hline Type of feedback & Content & Organization & Linguistic accuracy & Requirements & Total \\
\hline $\begin{array}{c}\text { Oral feedback } \\
(97)\end{array}$ & 52 & 24 & 211 & 334 \\
\hline $\begin{array}{c}\text { Written feedback } \\
(520)\end{array}$ & 61 & 49 & 304 & 106 & 520 \\
\hline Total & 113 & 73 & 515 & 153 & 854 \\
\hline
\end{tabular}

Students' experience in receiving feedback from the instructor: To answer the second research question, the findings obtained from the follow-up interviews with the students revealed their varying experience in receiving audio vs. written feedback from the instructor. The findings are discussed under the following themes generated from the thematic analysis of the follow-up interviews:

Students' overall positive experience: The findings revealed that the students described their experience as the first time-experience in receiving feedback from the instructor on their assignments at the university. All students stated that it was their first time though some of them pointed at that they received feedback from other instructors on their assignments in other courses. Yet, such feedback they received in other courses is only provided one time after submission of the assignments at the end of the semester:

S10: As a first timer- I mean the first time for me to receive feedback, I did not expect that I would receive constant feedback from the doctor. You know? because in other courses, we just receive small comments on our final assignments at the last week of the semester.

In addition, almost all students reported their interesting experience in receiving feedback from the instructors on their assignments over the academic semester. Their responses to the second interview questions are evident of their positively perceived experience in receiving such formative feedback on their assignments. Some of them also justified their positive views on their experience as receivers of feedback by the guidance, instruction and assistance they received through the instructor's feedback in doing their assignments and successfully accomplishing them:

S22: Yes, definitely Dr's feedback was invaluable because guidance was available each step of the way.

S19: It was a great experience because the instructor used many types of feedback which were really helpful on guiding me on doing the assignments.

Students' varying preference for feedback: The findings obtained from the students' responses to the third question in the interview displayed that their preference for the type of feedback received from the instructor on their assignments varied from their like for written feedback (16 students) to their preference for audio feedback over written feedback (14 students). These varying preferences are illustrated by the following sample responses extracted from the transcripts of the follow-up interviews:

S8: Probably, I would prefer written over the audio feedback.

S24: I would say audio feedback over written feedback.

The students' responses to the fourth and fifth questions in the interview revealed interesting findings underlying the reasons behind students' varying preferences for receiving feedback and provided more elaborations of the perceived value and disvalue of audio vs. written feedback. These findings are interpreted under two conceptual themes: the perceived advantages and the perceived disadvantages of audio vs. written feedback from the students' viewpoints as follows:

Perceived advantages of audio vs. written feedback: Regarding the perceived advantages of the written feedback, most of the 16 students who hold preference for written feedback highlighted the features of the written feedback: clarity, easiness in understanding the intended message, easy access to feedback and its focus on a certain issue in the assignments. These features are illustrated in the following students' sample voices in the interview:

S16: I can say I have one reason. I prefer written feedback as I could see the points clearer and refer back easier.

S14: Written feedback is easier to read it when revising and easier to be understood.

S2: As I said written feedback because I can focus on an important point in my assignment.

The above findings do not mean that all the 16 students disliked the audio feedback as some of them (7) in responding to the fifth question of the interview pointed at the positive features of the audio feedback. Thus, their responses in combination to the responses of the nine students who preferred audio feedback over written feedback indicate that audio feedback is advantaged for being comprehensive or detailed, simple and conducive to students' development of a sense of their serious issues and flaws in the assignments:

S18: The audio feedback was very good in details and very helpful. I learnt a lot through the feedback actually.

S9: I like the fact that the teacher's audio feedback was simple. I mean using simple words.

S1: By listening to teacher's intonation, we could grasp the severity of our mistake.

Perceived disadvantages of audio feedback: From the above findings, there were some disadvantages of audio, which made most of the students prefer the written feedback over audio feedback I this study. First, almost 13 students pointed at the confusion of audio feedback. Since each audio feedback focused on several issues and flaws of students' assignments, it became confusing for those students to focus on all issues while listening to it and revising their assignments: 


\section{S4: Through audio sometimes I get lost listening to it.}

Moreover, due to the detailed nature of audio feedback as illustrated in the above samples, some students (8 students) misunderstood some points carried out by the audio feedback. As a result, they got lost about what to focus on while listening to the audio feedback and revising their assignments:

S17: Sometimes audio feedback was long and I had to re-play them for many times, just to check on one sentence in the audio.

Another related disadvantage of audio feedback as perceived by eleven students is the quality of audio feedback. Regarding this, they pointed at the external noises they heard in the recorded audio files, which distracted them from clearly listening to the main points on their issues and flaws in the assignments:

S6: One reason is due to the external noises that could disrupt the audio and the listener having to misheard some messages along the way or hearing mispronunciation of some words.

A final challenging issue that led to some students' perceived disadvantages of audio feedback is the difficulty involved in accessing the audio feedback recorded and posted in the form of comments in the Google Docs pages. Almost seven students pointed at this challenge, which disturbed their convenient access and listening to audio feedback:

S10: I think part of why I prefer written feedback compared to audio feedback was because I could not play certain audio feedback on the devices that I use to write my assignments.

\section{DISCUSSION}

In accordance with the first research question, the findings revealed the instructor's audio and written feedback differed in relation to its quantity. Specifically, the number of written comments provided over the study period was higher than that of the audio comments. Apparently, this finding could be due to the drafts on which the feedback was provided. In other words, the written feedback was provided on the first drafts of students with more issues and flaws as opposed to the second drafts on which he provided the audio feedback. However, this finding cannot be fully and accurately interpreted this way because our further analyses of the content of both modes of feedback provided better insights into the differences between the two modes of feedback, which helped in interpreting this finding.

Based on our content analysis of the actual feedback in both modes, we could observe the efficiency of audio feedback in comparison to written feedback in several ways. First, each comment in the audio feedback data consisted of more than one pragmatic function. This finding suggests that the audio feedback was more potential in terms of its composition and providence or delivery than written feedback. In other words, the instructor could provide a high number of feedback in terms of its pragmatic functions through a low number of audio feedback comments. This finding supports the efficacy of audio feedback in relation to its being economical and time-efficient (Hennessy \& Forrester, 2014; Rodway-Dyer et al. 2011; Parkes \&Fletcher, 2016).

Our findings also indicate that audio feedback is more effective than written feedback in regard to its foci. Since the quality of teacher feedback is largely judged or evaluated by its content or the information it delivers to students (e.g., Hennessy \& Forrester, 2014), our findings obtained from the content analysis of the instructor's feedback provided evidence illustrating how the instructor could target more than one issue in one audio feedback comment. Audio feedback can be a tool for carrying rich and detailed information (e.g, Oldfield, 2016; Hennessy \& Forrester, 2014; Ice et al., 2010; Lunt \& Curran, 2010; Olesova et al., 2011). Yet, our study contributes to this body of previous research on this potential of audio feedback based on an actual analysis of feedback rather than mere analysis of students' perception of feedback. There are only two studies focusing on the actual analysis of both modes of feedback (RodwayDyer et al., 2011; Voelkel \& Mello, 2014) though these studies did not focus on analyzing both modes of feedback in relation to its pragmatic functions.

In addition, as shown by our finding on the overall number of issues and flaws targeted by audio and written feedback, the nature of issues in students' writing affects the way instructors use audio or written feedback. First, the audio feedback targeted more content-related issues than written feedback could be due to the suitability of audio feedback for issues and flaws in the area of content which appear more complex and require more detailed explanations from the instructor. On the other hand, the higher number of issues and flaws in linguistic accuracy and appropriateness was targeted by the written feedback in this study. This could be due to the fact that since issues and flaws related to language and requirements seem less important and less complex, it is convenient to target such issues through written comments. This is in agreement with some other studies which highlighted the perceived value of written feedback in identifying local or micro-level issues in students' written tasks from students' perspectives (e.g., Ice et al. 2010; Still, 2006) and also from an empirical analysis of both modes of feedback (Rodway-Dyer et al., 2011; Voelkel \& Mello, 2014) .

As an answer to the second research question of the study, our findings demonstrated that the students described their overall positive experience in reviving feedback from the instructor on their written assignments. Such positive experience could be due to the students' first time in receiving formative feedback on their assignments at college. This finding corroborates those of previous research on students' valuing of their experience in receiving feedback from the instructors (Fawcett \& Oldfield, 2016; Rodway-Dyer et al., 2011). The students also compared such formative feedback to the feedback of instructors in other courses and recognized the continuous support received through the instructor's formative feedback on their assignment. As they constantly received the feedback over the semester from the start of 
writing their assignments till the end of the semester, the students could perceive the value of such formative feedback through the support, guidance, identification of issues and flaws in their writing and suggestions on enhancing their written tasks. This finding does not only support empirical studies on the value of instructors' formative feedback (Hennessy \& Forrester, 2014; Ice et al., 2010; Lunt \& Curran, 2010; Olesova et al., 2011), but also contributes to our understanding of conceptualization of such feedback as scaffolding or assistance from the sociocultural theory (Vygotsky, 1978). We can, therefore, confirm that instructor feedback is a vehicle for scaffolding or assistance provided by more capable others (instructors) to learners to successfully accomplish their tasks and enhance their learning (Hyland \& Hyland, 2006; Lee, 2014; Nassaji \& Swain, 2000).

Despite the efficacy of audio feedback supported by our content analysis of the actual feedback on the students' assignments, the findings obtained from the follow-up interviews or reflections of students are somehow contradictory. First, most of the students preferred written feedback over audio feedback though the difference in the numbers of students (16) displaying preference for written feedback and students displaying preference for audio feedback (16) is not high. While such finding also contradicts those findings reported by most previous studies on students' high preference for audio feedback over written feedback (Fawcett \& Oldfield, 2016; Hennessy \& Forrester, 2014; Ice et al., 2010; Lunt \& Curran, 2010; Olesova et al., 2011; Rodway-Dyer et al., 2011; Parkes \& Fletcher, 2016; Voelkel \& Mello, 2014), it is in an agreement with findings of some other studies (Fawcett \& Oldfield, 2016; Johnson \& Cooke, 2015; Olesova et al., 2011).

In exploring the main reasons behind those students' preference for written feedback over audio feedback, our findings highlighted some reasons which could be disadvantages of audio feedback. One of the main reasons is students' confusion as a result of the detailed instruction provided through the audio feedback. Although this detailed instruction is considered as one advantages of audio feedback in our analysis of the actual feedback and in several previous studies based on students' perception of feedback (Hennessy \& Forrester, 2014; Gould \& Day, 2013; Lunt \& Curran, 2010; Rodway-Dyer et al., 2011), it was perceived by those students as a barrier for them for it distracted their attention from listening to the main point in order to revise their assignments in this study. Therefore, we suggest that instructors should minimize the detailed instruction when delivering feedback to students through audio records in order to help them get the main points clearly.

Another reason behind students' high preference for written feedback over audio feedback was the poor quality of records in the feedback files. In this regard, an important issue concerning audio feedback is the quality of recording (Hennessy \& Forrester, 2014; Olesova et al., 2011; Parkes \& Fletcher, 2016). This becomes a challenging issue for students who receive audio feedback since the presence of external noises while recording the feedback will disturb students from well listening to the intended suggestions in such records. This will also affect their positive experience in receiving audio feedback from instructors. Therefore, it is advisable for instructor to make sure that the environment where they record their feedback is free-noise and calm.

Another issue stated as one reason behind students' preference for written feedback is related to one disadvantage of audio feedback is the difficulty experienced by some students in accessing the audio feedback recorded and posted as links in the form of comments in the Google Docs pages. Although the students were instructed on the impotence of uploading the program related to the audio feedback, this was perceived by some students as a barrier. Interestingly, the issue here is not the same technical issue, which is unsuitable recording as identified in some previous studies identified technical issues with unsuitable recording devices (e.g., Emery \& Atkinson, 2009; Johnson \& Cooke, 2015), but rather it is concerned with students' preparation (e.g., downloading the programs in their laptop or mobile devices). Therefore, a good preparation of students for feedback should ensure that they are all able to access the feedback easily in order to avoid such emerging issues during the feedback implementation stage.

These issues could be the main reasons why those students perceived the value of written feedback in terms of its clarity, easiness in understanding the intended message, easy access to feedback and its focus on a certain issue in the assignments though they could recognize certain advantages of audio feedback in relation to its comprehensiveness or details, simplicity and its role in helping them develop a sense of their serious issues and flaws in the assignments. Such finding could be also interpreted from the good standard or quality of written feedback provided to the students in this study, which was also reported in a previous study (Fawcett \& Oldfield, 2016). In both studies, the written feedback was typed rather than hand-written, which could contribute to students' high preference for written feedback over audio feedback.

\section{CONCLUSION}

Despite the detailed findings on both modes of feedback in this study, there are several limitations that should be addressed for future research. First, our content analysis of both modes of feedback focused on the overall feedback provided on the fifteen pairs of students. However, future research should also compare both modes as distributed among the pairs to find out further differences. Moreover, this study was not intended to determine the role of both modes of feedback on students' written tasks. Therefore, future studies focusing on this aspect can do so by assessing the quality of students' tasks at the end of each stage. Another limitation is that this study focused on male students due to the culture that separates males from females in the study content, which might have affected our findings. 


\section{REFERENCES}

[1] Aljaafreh, A., \& Lantolf, J. P. (1994). Negative feedback as regulation and second language learning in the zone of proximal development. The Modern Language Journal, 78(4), 465-483.

[2] Cavanaugh, A. J., \& Song, L. (2014). Audio feedback versus written feedback: Instructors' and students' perspectives. MERLOT Journal of Online Learning and Teaching, 10, 122-137.

[3] Dixon, S. (2015). The pastoral potential of audio feedback: A review of the literature. Pastoral care in Education, 33(2), 96104.

[4] Fawcett, H., \& Oldfield, J. (2016). Investigating expectations and experiences of audio and written assignment feedback in first-year undergraduate students. Teaching in Higher Education, 21(1), 79-93.

[5] Gould, J., \& Day, P. (2013). Hearing you loud and clear: student perspectives of audio feedback in higher education. Assessment \& Evaluation in Higher Education, 38(5), 554-566.

[6] Hennessy, C., \& Forrester, G. (2014). Developing a framework for effective audio feedback: a case study. Assessment \& Evaluation in Higher Education, 39(7), 777-789.

[7] Hyland, F. (2010). Future directions in feedback on second language writing: Overview and research agenda. International Journal of English Studies, 10(2), 171-182.

[8] Hyland, K., \& Hyland, F. (2006). Feedback on second language students' writing. Language teaching, 39(2), 83-101.

[9] Ice, P., Curtis, R., Phillips, P., \& Wells, J. (2007). Using asynchronous audio feedback to enhance teaching presence and students' sense of community. Journal of Asynchronous Learning Networks, 11(2), 3-25.

[10] Ice, P., Swan, K., Diaz, S., Kupczynski, L., \& Swan-Dagen, A. (2010). An analysis of students' perceptions of the value and efficacy of instructors' auditory and text-based feedback modalities across multiple conceptual levels. Journal of Educational Computing Research, 43(1), 113-134.

[11] Johnson, G. M., \& Cooke, A. (2016). Self-regulation of learning and preference for written versus audio-recorded feedback by distance education students. Distance Education, 37(1), 107-120.

[12] Lee, I. (2014). Revisiting teacher feedback in EFL writing from sociocultural perspectives. TESOL Quarterly, 48(1), $201-213$.

[13] Lunt, T., \& Curran, J. (2010). 'Are you listening please?' The advantages of electronic audio feedback compared to written feedback. Assessment \& evaluation in higher education, 35(7), 759-769.

[14] Macgregor, G., Spiers, A., \& Taylor, C. (2011). Exploratory evaluation of audio email technology in formative assessment feedback. Research in Learning Technology, 19(1), 39-59.

[15] Nassaji, H., \& Swain, M. (2000). A Vygotskian perspective on corrective feedback in L2: The effect of random versus negotiated help on the learning of English articles. Language awareness, 9(1), 34-51.

[16] Nicol, D. J., \& Macfarlane-Dick, D. (2006). Formative assessment and self-regulated learning: A model and seven principles of good feedback practice. Studies in higher education, 31(2), 199-218.

[17] Olesova, L., Richardson, J., Weasenforth, D., \& Meloni, C. (2011). Using asynchronous instructional audio feedback in online environments: A mixed methods study. MERLOT Journal of Online Learning and Teaching, 7(1), 30-42

[18] Parkes, M., \& Fletcher, P. (2017). A longitudinal, quantitative study of student attitudes towards audio feedback for assessment. Assessment \& Evaluation in Higher Education, 42(7), 1046-1053.

[19] Rodway-Dyer, S., Knight, J., \& Dunne, E. (2011). A case study on audio feedback with geography undergraduates. Journal of Geography in Higher Education, 35(2), 217-231.

[20] Still, B. (2006). Talking to students: Embedded voice commenting as a tool for critiquing student writing. Journal of Business and Technical Communication, 20(4), 460-475.

[21] Voelkel, S., \& Mello, L. V. (2014). Audio Feedback-Better Feedback?. Bioscience Education, 22(1), 16-30.

[22] Vygotsky, L. (1978). Interaction between learning and development. Readings on the development of children, 23(3), 34-41.

Mohammed Abdullah Alharbi is an associate professor in the Department of English at Majmaah University, Saudi Arabia. His research interests include L2 writing instruction, computer-mediated communication, peer review, and peer interaction.

Abdurrazzag Alghammas is an associate professor of applied linguistics at Qassim University, Saudi Arabia. He has been teaching English courses for secondary-level and university-level students since 2002. He obtained a Master's degree in Applied Linguistics from The University of Edinburgh, UK, and a PhD in Applied Linguistics from The University of Memphis, USA. His research interests include computer-assisted language teaching and learning, second language acquisition and assessment. 